\title{
Comparison of PCR-Based Molecular Markers for the Characterization of Proteus mirabilis Clinical Isolates
}

\author{
Lessandra Michelim, Gabriela Muller, Jucimar Zacaria, Ana Paula Longaray Delamare, Sérgio Olavo Pinto da Costa and \\ Sergio Echeverrigaray \\ Institute of Biotechnology, University of Caxias do Sul; Caxias do Sul, RS, Brazil
}

\begin{abstract}
Proteus mirabilis is one of the most important pathogens associated with complicated urinary tract infections (acute pyelonephritis, bladder infections, kidney stones) and bacteremia, affecting patients with anatomical abnormalities, immunodeficiency, and long-term urinary catheterization. For epidemiological purposes, various molecular typing methods, such as pulse-field gel electrophoresis (PFGE) or ribotyping, have been developed for this pathogen. However, these methods are labor intensive and time-consuming. We evaluated the discriminatory power of several PCR-based fingerprinting methods (RAPD, ISSR, ERIC-PCR, BOX-PCR and rep-PCR) for P. mirabilis clinical isolates. Typing patterns and clustering analysis indicated that RAPD, BOX-PCR and ERIC-PCR differentiated $P$. mirabilis strains from Escherichia coli, Hafnia alvei, and Morganella morganii. With the exception of rep-PCR, the methods gave medium to high discriminatory efficiency in P. mirabilis. In general, the results obtained with RAPD, BOX-PCR and ERIC-PCR were in good agreement. We concluded that a combination of ERIC-PCR and BOX-PCR results is a rapid and reliable alternative for discrimination among $P$. mirabilis clinical isolates, contributing to epidemiological studies.

Key-Words: Proteus mirabilis, molecular markers, fingerprinting, PCR.
\end{abstract}

Proteus mirabilis (Enterobacteriaceae) is a Gram-negative rod-shaped bacterium, frequently found in soil, water and the intestinal tract of many animals, including humans. This dimorphic bacterium can undergo morphological and physiological changes in response to environmental and growth conditions. These modifications lead to its most peculiar characteristic, swarming behavior, a process in which short vegetative swimming cells differentiate to long, highly flagellated forms referred to as swarmer cells [1].

Proteus mirabilis is not a common cause of urinary tract infections in normal hosts, occasionally involved in uncomplicated cystitis or pyelonephritis. However, it is one of the most important pathogens associated with complicated urinary tract infections (acute pyelonephritis, bladder infections, and kidney stones) and bacteremia, affecting patients with anatomical abnormalities, immunodeficiency, and long-term urinary catheterization [1-3]. Proteus mirabilis virulence is associated with several virulence factors, including hemolysin, swarming, adhesins, proteases, and ureases [4-6]. Expression of most of these factors is coordinately upregulated during swarming [6-8].

Because of the increasing clinical relevance of $P$. mirabilis [3], the selection of efficient molecular fingerprinting methods is of great epidemiological importance. Bacterial genotyping opened new opportunities for epidemiological studies, allowing the identification of clinical and environmental Received on 15 May 2008; revised 10 September 2008.

Address for correspondence: Dr. Lessandra Michelim, Laboratório de Biotecnologia Vegetal e Microbiologia Aplicada. Instituto de Biotecnologia da Universidade de Caxias do Sul. R. Francisco G. Vargas 1130, Petrópolis. Zip code: 95001-970. Caxias do Sul, RS, Brazil. Phone: (54) 32146750. Fax: (54) 32187237. Cellphone: (54) 991229469. E-mail: lessandra@gmail.com.

The Brazilian Journal of Infectious Diseases Publishing. All rights reserved. isolates, evaluation of their relationships, monitoring of clone dissemination, and characterization of bacterial populations within more or less restricted environments [9]. Among PCRbased molecular markers, RAPD (random amplified polymorphic DNA), and repetitive sequence-based PCR genomic fingerprinting have been found to be particularly efficient for bacterial analysis [9-13]. Repeated sequences ERIC (enterobacterial repetitive intergenic consensus sequence), REP (repetitive extragenic palindromic sequence), and BOX (repetitive intergenic sequence elements of Streptococcus) have been specifically designed for prokaryotic fingerprinting.

Ribotyping and PFGE (pulsed-field gel electrophoresis) are efficient for Proteus characterization at the species level [14] and for identification of individual strains of $P$. mirabilis $[15,16]$. However, these methods are laborious, expensive, and time consuming, limiting their application in routine clinical laboratories [9]. RAPD, a PCR-based method, has been used with success in the identification of clinical isolates of $P$. mirabilis [17] and $P$. penneri [18]. More recently, the tandem tetramer microsatellites (GACA) 4 and (CAAT), also known as intergenic single sequence repeats (ISSR), have given a high degree of discrimination for $P$. mirabilis [19].

We evaluated and compared the efficiency of five PCRbased molecular markers for the characterization of $P$. mirabilis clinical isolates, in order to select informative markers for epidemiological studies, and to monitor $P$. mirabilis populations within hospital environments.

\section{Material and Methods}

Bacterial Isolates

Thirty-three clinical isolates, (29 P. mirabilis, one Escherichia coli, one Hafnia alvei and two Morganella morganii) were obtained from the Hospital Geral de Caxias do Sul, Caxias do Sul, Brazil (Table 1). These clones were isolated 
by routine procedures for the different sample sources, and were identified by conventional microscopic and biochemical tests: Gram staining, motility, swarming behavior, indole production, phenylalanine dehydrogenase, ornithine decarboxylase, gas production from glucose, $\mathrm{H}_{2} \mathrm{~S}$ production, urease, tryptophan deaminase, lysine decarboxylase, and citrate and lactose utilization. Antibiotic resistance was evaluated by the disc-diffusion method and analyzed as described by CLSI document M100-S17 [20].

Bacterial isolates were maintained on trypticase soybean agar (TSA), and permanent stocks were conserved on TSBG (tryptone soy broth with $15 \%$ glycerol) at $-80^{\circ} \mathrm{C}$. For DNA analysis, single colonies were transferred to $1 \mathrm{ml}$ of $\mathrm{LB}$ (Luria Broth) and incubated at $37^{\circ} \mathrm{C}$ for $18 \mathrm{~h}$.

\section{PCR Fingerprinting}

DNA samples were prepared as described by Lu [4], with some modifications. Briefly, single colonies of each isolate were inoculated on LB medium and grown overnight at $37^{\circ} \mathrm{C}$. Cells were collected by centrifugation at 13,000 x g for $5 \mathrm{~min}$, and ressuspended in $100 \mathrm{~mL}$ of extraction buffer (1\% Triton-X-100, $100 \mathrm{mM}$ Tris-HCl pH 8.3, and 1mM EDTA). The samples were incubated for $20 \mathrm{~min}$ in a boiling water bath $\left(100^{\circ} \mathrm{C}\right)$ and centrifuged at $13,000 \mathrm{xg}$ for $5 \mathrm{~min}$. The supernatant was transferred to a new tube containing $180 \mathrm{~mL}$ of ultrapure Milli-Q(Millipore) water. Samples were aliquoted and conserved at $-80^{\circ} \mathrm{C}$.

For RAPD, ERIC, BOX and REP analysis, $2 \mathrm{~mL}$ of the DNA samples were transferred to $23 \mathrm{~mL}$ of amplification mix containing: 20mM Tris- $\mathrm{HCl} \mathrm{pH} 8.4,50 \mathrm{mM} \mathrm{KCl,} 7 \mathrm{mM} \mathrm{MgCl}_{2}$, $0.25 \%$ Triton-X-100, $8 \mathrm{mM}$ dNTPs, $1 \mathrm{mM}$ of each primer (ERIC and REP) or $1.5 \mathrm{mM}$ of the primer for RAPD and BOX, and 1.25U of Taq Polymerase (Invitrogen). DNA amplification was conducted on a MJ Research thermocycler programmed for an initial denaturation step at $92^{\circ} \mathrm{C}(4 \mathrm{~min})$, followed by 40 cycles of denaturation for $1 \mathrm{~min}$ at $94^{\circ} \mathrm{C}$, annealing for $1 \mathrm{~min}$ at the appropriate temperature (RAPD and REP- $40^{\circ} \mathrm{C}$, ERIC- $48^{\circ} \mathrm{C}$, and $\mathrm{BOX}-50^{\circ} \mathrm{C}$ ), extension for $5 \mathrm{~min}$ at $72^{\circ} \mathrm{C}$, and a final extension for $5 \mathrm{~min}$ at $72^{\circ} \mathrm{C}$. Samples were maintained at $4^{\circ} \mathrm{C}$ until electrophoretic separation of amplification products.

The primers used were: ERIC-1R (5'ATGTAAGCTCCTGGGGATTCAC-3') and ERIC-2 (5'AAGTAAGTGACTGGGGTGAGCG-3'), and REP-PCR-1R (5'IIIICGICGICATCIGGC-3'), and REP-PCR-2I (5'ICGICTTATCIGGCCTAC-3'), described by Versalovic et al. [21], BOX-A1R (5'-CTACGGCAAGGCGACGCTGACG-3') previously used for several bacterial species [11,12,22], and RAPD and ISSR (Table 2).

The amplification reaction for ISSR markers included $2 \mathrm{~mL}$ of DNA samples and $23 \mathrm{~mL}$ of a PCR mix, including $20 \mathrm{mM}$ Tris- $\mathrm{HCl} \mathrm{pH}$ 8.4, 50mM KCl, 3mM $\mathrm{MgCl}_{2}$, 2\% formamide, $0.75 \mathrm{mM}$ of each dNTP, $1 \mathrm{mM}$ of each primer and $1.5 \mathrm{U}$ of Taq Polymerase (Invitrogen). For the DNA amplification, the reaction mixture was denatured for $5 \mathrm{~min}$ at $92^{\circ} \mathrm{C}$, followed by 40 cycles at $94^{\circ} \mathrm{C}(1 \mathrm{~min}), 48^{\circ} \mathrm{C}$ to $50^{\circ} \mathrm{C}(45 \mathrm{~s})$ and $72^{\circ} \mathrm{C}(2 \mathrm{~min})$, with a final extension for $5 \mathrm{~min}$ at $72^{\circ} \mathrm{C}$.
The amplification products were electrophoresed in $1.5 \%$ agarose gels in Tris-borate buffer (0.089M Tris, 0.089M boric acid, 0.002M EDTA). Lambda EcoRI/HindIII was used as a molecular size standard. The gels were stained with ethidium bromide $(10 \mathrm{mg} / \mathrm{mL})$, visualized on a UV light transilluminator, and documented with the UVITEC system. Image analyses were carried out using Labimage software.

The amplifications with the five methods were repeated three times (independent cultures and DNA extractions) to evaluate reproducibility, with two replications of each isolate per round. Only well defined and reproducible amplification products (presence and intensity) were scored and used in statistical analyses.

\section{Statistical Analysis}

Similarity Jaccard's coefficients, Pearson's correlation between distance matrices, and cluster analysis (unweighted pair-group method with average linkage - UPGMA) were performed using the SSCP 10.1 software package. Bootstrap analysis was done with the Winboot program. The discriminatory index (DI) was calculated from the relative frequencies of the different profiles obtained by a given primer or method, and was calculated using Simpson's diversity index [23], as follows:

$$
\mathrm{DI}=1-\left\{\sum n_{j}\left(n_{j}-1\right) /[N(N-1)]\right\}
$$

Where $N$ is the total number of isolates and $n_{j}$ is the number of isolates belonging to the $j$ th type.

\section{Results}

RAPD Typing

Initially, a set of 10 decameric RAPD primers (Table 2) were selected from the 60 primers of kits A, X and Z of Operon Techn., based on the number, quality and polymorphisms of amplification products, using three arbitrarily-chosen $P$. mirabilis isolates (IBPro 101, IBPro102 and IBPro120). Applied to all the isolates, these primers generated 188 amplification products, varying between 300 and 2,445 bp. Considering just the 29 Proteus isolates, 86 bands were identified, of which 51 (59\%) exhibited some degree of polymorphism. Each decameric primer amplified from 3 to 14 segments, of which 25 to $80 \%$ were polymorphic.

Thirty-five Proteus-specific amplification products were identified that can be used to design Proteus-specific SCAR primers (Table 2). An example of RAPD profiles showing three Proteus-specific bands of 2113bp, 831bp and 431bp, and several polymorphic bands, is shown in Figure 1. Considering all the amplification products, RAPD markers allowed the discrimination of almost all the isolates, except for three isolates obtained from patient 10 (IBPro 111, 112 and 116), two isolates (IBPro 121 and IBPro 122) from hemocultures of patient 18, and isolates IBPro 102 and 131, obtained from foot secretions and a skin biopsy of patient 9 (Figure 2). These isolates showed the same antibiotic resistance patterns (Table 1) and Dienes types (data not shown). 
Table 1. List of isolates, their origin, sample source, and antibiotic resistance.

\begin{tabular}{|c|c|c|c|c|c|c|c|}
\hline $\begin{array}{l}\text { Identification } \\
\text { number* }\end{array}$ & Patient & Age & Sex & $\begin{array}{l}\text { Sample } \\
\text { origin }^{* *}\end{array}$ & Date & $\begin{array}{l}\text { Sample } \\
\text { source }\end{array}$ & Antibiotic resistance ${ }^{* * *}$ \\
\hline IBPro101 & 01 & 53 & $\mathrm{M}$ & C.U. $6^{\circ}$ & $18 / 05 / 04$ & Pulmonary secretion & n.d. \\
\hline IBPro102 & 02 & 45 & M & ICU Adults & $17 / 05 / 04$ & Thoraxic drain & AMP, CIP, SUT \\
\hline IBPro105 & 05 & 71 & $\mathrm{~F}$ & C.U. $5^{\circ}$ & $23 / 05 / 04$ & Urine & NIT \\
\hline IBPro106 & 06 & 57 & $\mathrm{~F}$ & ICU Adults & $24 / 05 / 04$ & Sputum & AMP \\
\hline IBPro107 & 07 & 66 & $\mathrm{M}$ & C.U. $5^{\circ}$ & 09/06/04 & Sputum & CIP \\
\hline IBPro109 & 09 & 82 & $\mathrm{M}$ & C.U. $6^{\circ}$ & $31 / 05 / 04$ & Foot secretion & n. d. \\
\hline IBPro110 & 09 & 82 & $\mathrm{M}$ & C.U. $6^{\circ}$ & 02/06/04 & Skin biopsy & AMP, CEF \\
\hline IBPro111 & 10 & 1 & $\mathrm{M}$ & ICU Pediatric & 02/06/04 & Tracheal secretion & AMP, GEN, SUT \\
\hline IBPro112 & 10 & 1 & $\mathrm{M}$ & ICU Pediatric & 08/06/04 & Tracheal secretion & AMP, GEN, SUT \\
\hline IBPro113 & 11 & 64 & M & E.U. & 08/06/04 & Sputum & n. d. \\
\hline IBPro114 & 12 & 41 & $\mathrm{~F}$ & Chirurgical center & $18 / 05 / 04$ & Abdominal hematoma & $\begin{array}{l}\text { AMI, AMP, AMS; CEF; } \\
\text { CXN.; CRO; CIP; SUT }\end{array}$ \\
\hline IBPro115 & 13 & 84 & $\mathrm{M}$ & Community & 03/06/04 & Urine & $\begin{array}{l}\text { AMP, CEF; CXN; GEN, } \\
\text { NIT, NOR, SUT }\end{array}$ \\
\hline IBPro116 & 10 & 1 & M & ICU Pediatric & 09/06/04 & Ear secretion & AMP, GEN, SUT \\
\hline IBPro118 & 15 & 29 & $\mathrm{~F}$ & S.M.T. & $30 / 07 / 04$ & Urine & NIT \\
\hline IBPro119 & 16 & 44 & M & C.U. $6^{\circ}$ & $30 / 06 / 04$ & Urine & AMP, NIT, NOR, SUT \\
\hline IBPro120 & 17 & 47 & $\mathrm{~F}$ & O.C. & $14 / 07 / 04$ & Urine & AMP, NIT, SUT \\
\hline IBPro121 & 18 & 71 & $\mathrm{M}$ & E.U. & $23 / 06 / 04$ & Blood culture & AMP, SUT \\
\hline IBPro122 & 18 & 71 & $\mathrm{M}$ & E.U. & 17/06/04 & Blood culture & AMP, SUT \\
\hline IBPro123 & 19 & 20 & $\mathrm{~F}$ & Community & $30 / 06 / 04$ & Urine & NIT \\
\hline IBPro124 & 20 & 79 & $\mathrm{M}$ & E.U. & $14 / 07 / 04$ & Blood culture & AMP, CIP, SUT \\
\hline IBPro125 & 21 & 56 & $\mathrm{~F}$ & Community & $29 / 06 / 04$ & Urine & AMP, NIT, NOR, SUT \\
\hline IBPro126 & 22 & 45 & $\mathrm{~F}$ & C.U. $5^{\circ}$ & 04/07/04 & Urine & AMP \\
\hline IBPro127 & 23 & 60 & $\mathrm{M}$ & C.U. $5^{\circ}$ & 23/07/04 & Urine & NIT \\
\hline IBPro128 & 24 & 60 & $\mathrm{~F}$ & Community & $22 / 07 / 04$ & Urine & NIT, SUT \\
\hline IBPro129 & 20 & 79 & $\mathrm{M}$ & C.U. $5^{\circ}$ & 23/07/04 & Urine & $\begin{array}{l}\text { AMP, CEF; NIT, NOR, } \\
\text { SUT }\end{array}$ \\
\hline IBPro130 & 25 & $<1$ & $\mathrm{M}$ & ICU Pediatric & 01/07/04 & Urine & AMP, NIT \\
\hline IBPro131 & 02 & 45 & $\mathrm{M}$ & ICU adults & 04/07/04 & Chirurgic Inf. & AMP, CIP, SUT \\
\hline IBPro132 & 26 & 73 & $\mathrm{~F}$ & C.U. $6^{\circ}$ & $26 / 06 / 04$ & Wound Inf. & AMP, CIP, SUT. \\
\hline IBPro133 & 27 & 49 & M & Community & $30 / 06 / 04$ & Urine & $\begin{array}{l}\text { AMP, CEF; CXN; NIT, } \\
\text { NOR, SUT }\end{array}$ \\
\hline IBHal103 & 03 & 51 & $\mathrm{~F}$ & C.U. $5^{\circ}$ & $19 / 05 / 04$ & Bile & AMP, CEF; CXN \\
\hline IBEsc104 & 04 & $<1$ & $\mathrm{~F}$ & E.U. & $20 / 05 / 04$ & Urine & n. d. \\
\hline IBMor108 & 08 & 73 & M & C.U. $5^{\circ}$ & $11 / 06 / 05$ & Foot abscess & AMP, SUT \\
\hline IBMor117 & 14 & 1 & $\mathrm{~F}$ & Community & $15 / 07 / 04$ & Urine & AMP, CEF; CXN, NIT \\
\hline
\end{tabular}

${ }^{*}$ IBPro - Proteus mirabilis; IBEco- Escherichia coli; IBMor- Morganella morganii; IBHal- Hafnia alvei. ${ }^{* *}$ C.U. - Care Unit $5^{\text {th }}$ or $6^{\text {th }}$ floor; O.C.Obstetric center; I.C.U.- Intensive Care Unit; C.C.- Chirurgical center; E.U.- Emergency Unit ${ }^{* *}{ }^{*}$ AMI- Amicacin; AMP- Ampicillin; AMSampicillin/sulbactam; $\mathrm{CEF}=$ cephalothin; $\mathrm{CXN}=$ cefoxitin; CRO.= ceftriaxone; CIP- ciprofloxacine; GEN- gentamicine; NIT- nitrofurantoin; NORnorfloxacine; SUT- sulfamethoxazol/trimethropim.

As expected, E. coli, M. morgani, and H. alvei were clearly differentiated from each other and from the $P$. mirabilis isolates (Figure 2).

\section{ISSR Fingerprinting}

Seven ISSR (intergenic single sequence repeats) primers were evaluated against three isolates of $P$. mirabilis (IBPro 101, IBPro102 and IBPro120). The primers used were (AC) $\mathrm{T},(\mathrm{AG})_{8} \mathrm{~A}$, $(\mathrm{GA})_{8} \mathrm{~T},(\mathrm{AG})_{8} \mathrm{YT},(\mathrm{GATA})_{4},(\mathrm{GACA})_{4}$, and (GTGC). No amplification was obtained with primer $(\mathrm{AG})_{8} \mathrm{YT}$; while primers
(GATA) $)_{4}$ and (GTGC) ${ }_{4}$ produced a smear. The other four primers generated well-defined amplification products (Figure 1). Applied to all the isolates, the selected primers generated 49 scorable bands, varying from 185 to $2,715 \mathrm{bp}, 38$ (77.5\%) of these bands were polymorphic within $P$. mirabilis. The main problem observed with ISSR markers was low reproducibility.

Considered together, the four ISSR primers allowed discrimination of all the isolates. However, the three outgroup species included in the analysis were clustered together with Proteus isolates. 
Table 2. Primer sequences.

\begin{tabular}{|c|c|c|c|c|c|}
\hline Primer & Primer sequences & $\begin{array}{l}\text { Total number } \\
\text { of bands }\end{array}$ & $\begin{array}{c}\text { Total number } \\
\text { of bands in Proteus }\end{array}$ & $\begin{array}{c}\text { Number of } \\
\text { polymorphic bands } \\
\text { in Proteus }\end{array}$ & $\begin{array}{l}\text { Simpson's diversity } \\
\text { index (DI) }\end{array}$ \\
\hline \multicolumn{6}{|l|}{ RAPD } \\
\hline OPA10 & 5' GTGATCGCAG 3' & 23 & 5 & 3 & 0.756 \\
\hline OPA11 & 5' CAATCGCCGT3' & 31 & 12 & 9 & 0.899 \\
\hline OPD20 & 5'ACCCGGTCAC3' & 9 & 3 & 2 & 0.333 \\
\hline OPX13 & 5'ACGGGAGCAA3' & 23 & 13 & 9 & 0.921 \\
\hline OPX15 & 5' CAGACAAGCC 3' & 15 & 8 & 2 & 0.563 \\
\hline OPZ04 & 5'AGGCTGTGCT 3' & 11 & 7 & 1 & 0.335 \\
\hline OPZ08 & 5'GGGTGGGTAA3' & 15 & 10 & 8 & 0.884 \\
\hline OPZ10 & 5' CCGACAAACC 3' & 16 & 7 & 5 & 0.627 \\
\hline OPZ19 & 5' GTGCGAGCAA3' & 26 & 14 & 7 & 0.847 \\
\hline \multirow[t]{2}{*}{ OPZ20 } & 5'ACTTTGGCGG 3' & 19 & 7 & 5 & 0.945 \\
\hline & & 188 & 86 & 51 & 0.998 \\
\hline ISSR 1 & $(\mathrm{AC})_{8} \mathrm{~T}$ & 15 & 15 & 15 & 0.953 \\
\hline ISSR 2 & $(\mathrm{AG})_{8} \mathrm{~A}$ & 12 & 12 & 5 & 0.829 \\
\hline ISSR 3 & $(\mathrm{GA})_{8}^{8} \mathrm{~T}$ & 6 & 6 & 2 & 0.458 \\
\hline \multirow[t]{2}{*}{ ISSR 6} & $(\mathrm{GACA})_{4}$ & 16 & 16 & 16 & 1.000 \\
\hline & & 49 & 49 & 38 & 1.000 \\
\hline 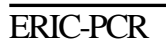 & ERIC 1R and ERIC 2 & 22 & 10 & 9 & 0.970 \\
\hline BOX-PCR & BOX-A1R & 20 & 12 & 10 & 0.980 \\
\hline REP-PCR & REP-PCR 1R and 2I & 14 & 4 & 2 & 0.621 \\
\hline
\end{tabular}

Table 3. Pearson product-moment correlation coefficient between similarity values obtained with genetic fingerprinting methods.

\begin{tabular}{lccccc}
\hline & BOX & REP & RAPD & ISSR & ERIC \\
\hline BOX & - & $0.712^{* *}$ & $0.848^{* *}$ & $0.054^{\mathrm{ns}}$ & $0.565^{* *}$ \\
REP & & - & $0.817^{* *}$ & $0.143^{*}$ & $0.670^{* *}$ \\
RAPD & & & - & $0.066^{\mathrm{ns}}$ & $0.693^{* *}$ \\
ISSR & & & & - & $0.161^{*}$ \\
ERIC & & & & & - \\
\hline
\end{tabular}

${ }^{*}$ Significant at $\mathrm{P}<0.05,{ }^{* *}$ Significant at $\mathrm{P}<0.01,{ }^{\text {ns }}$ Not significant.

Figure 1. Examples of the profiles obtained using the five PCR methods. A. RAPD OPA11, B. ERIC-PCR, C. ISSR 6, D. BOX-PCR, E. REP-PCR. Samples (from left) IB Pro101 and 102, IB Hal 103, IB Eco 104, IB Pro 105 to IB Pro 107, IB Mor 108, and IB Pro 109 and 110.
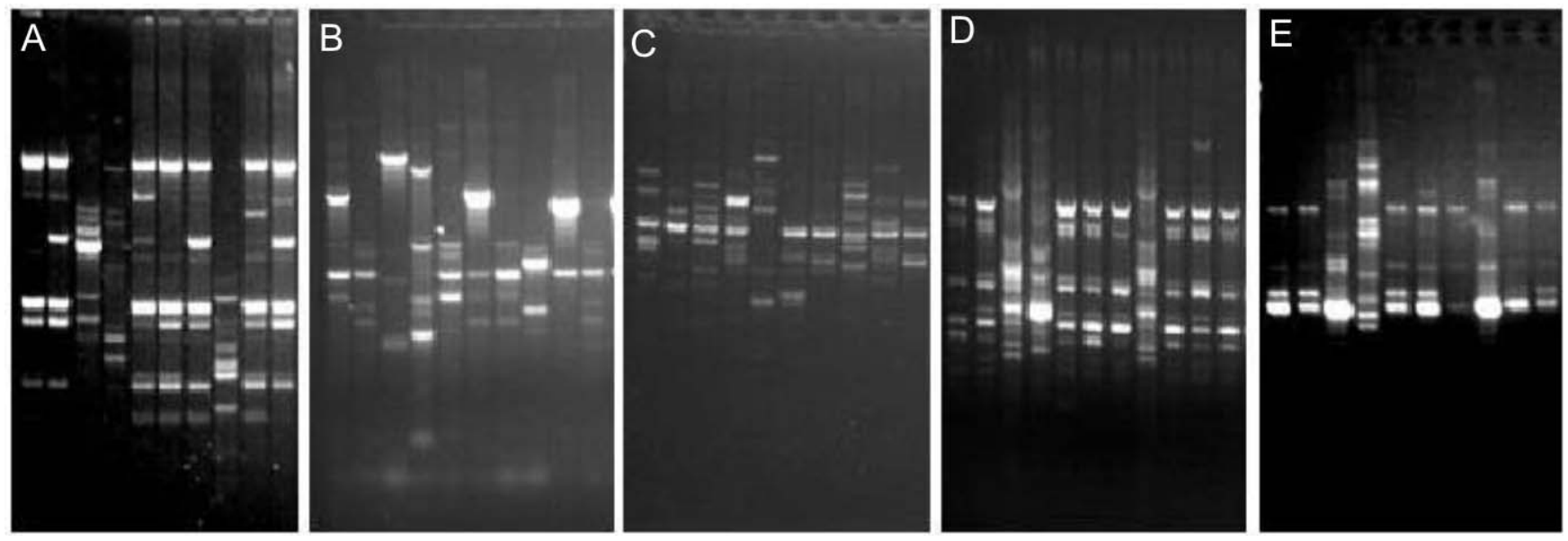

www.bjid.com.br 
Figure 2. Dendrograms obtained for Proteus mirabilis and outgroup species using different PCR fingerprinting methods. A. BOX, B. REP-PCR, C. RAPD, D. ISSR and E. ERIC-PCR.
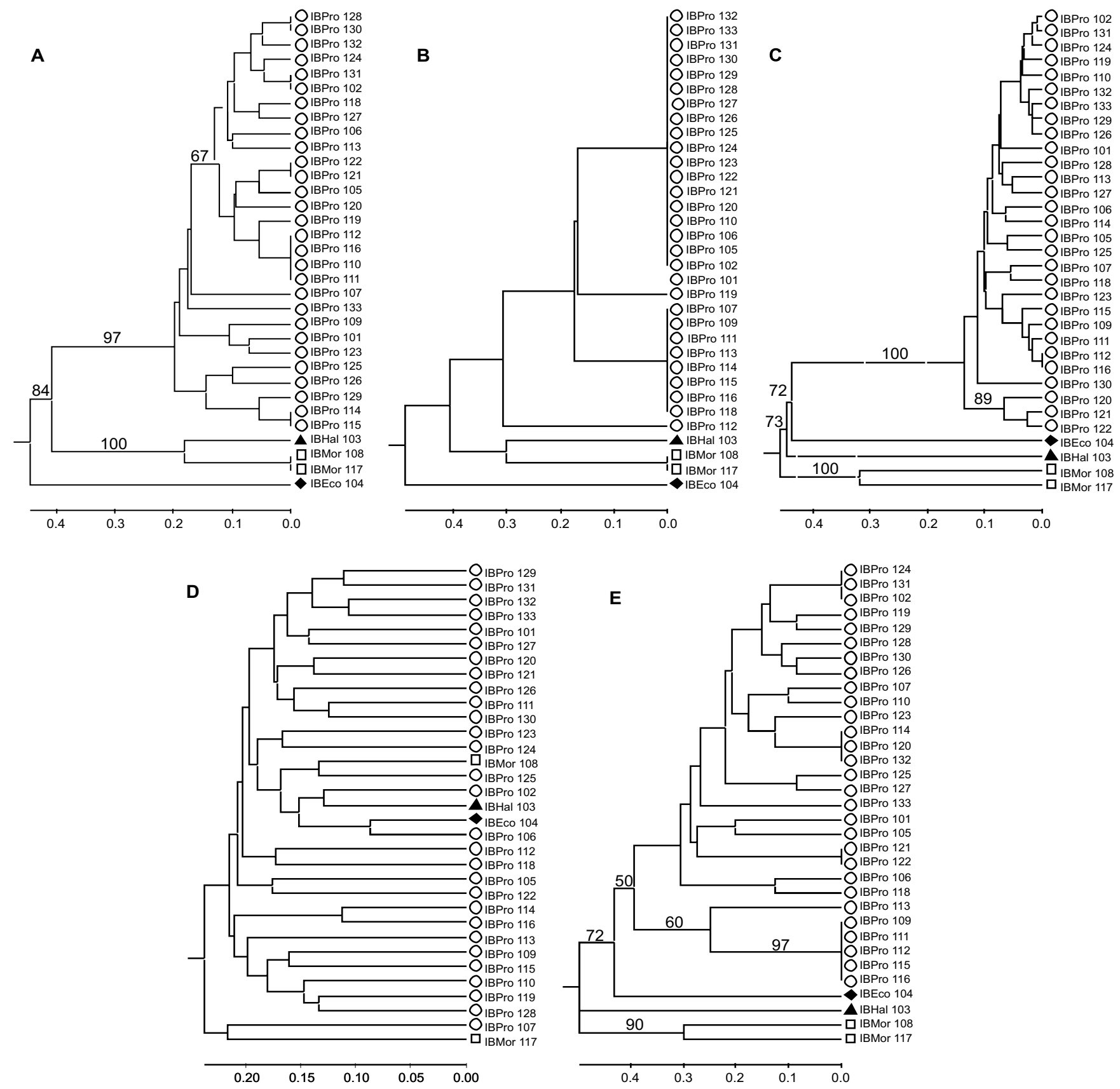

Repetitive-PCR Fingerprinting

As can be observed in Table 2 and Figure 1, ERIC-PCR and BOX-PCR resulted in detection of 10 and 12 amplification products in Proteus isolates, respectively. Nine of the 10 ERIC markers, and 10 of the 12 BOX markers exhibited some degree of polymorphism, being useful as discriminant markers. Three bands (ERIC-515bp, BOX-1199bp and BOX-402bp) were characteristic of $P$. mirabilis. As occurred with RAPD analysis, the control species (E. coli, $M$. morganii, and $H$. alvei) were clearly discriminated from each other, and from the Proteus isolates (Figure 2). Despite the low number of amplification

products obtained, ERIC-PCR and BOX markers allowed separating the 29 Proteus isolates into several groups (Figure 2). Moreover, these markers confirmed the identity of isolates IBPro 121 and 122 (patient 18), IBPro 102 and IBPro 131 (patient 9), and IBPro 111, 112 and 116 isolated from tracheal and ear secretions of patient 10 .

REP-PCR using primers $1 \mathrm{R}$ and 2I yielded 14 amplification products, which allowed the separation of the four bacterial species included in our analysis. A very low number of bands was obtained in $P$. mirabilis (four bands) with just two polymorphic products (769bp and 641bp), and a Proteus-specific product of 1,220 bp. 
Comparison of Methods

As can be observed in Table 2, the discriminatory index (Simpson's index), which represents the probability that two randomly chosen isolates will be distinguished by a given method, varied from 0.621 for REP-PCR to 1.000 for ISSR, with high values for RAPD, BOX and ERIC. Among RAPD primers, OPZ20, OPX13, OPA11, OPZ08 and OPA19 gave the highest DI values (Table 2). A high level of variation in the discriminatory indexes was also observed among ISSR primers; ISSR 1,2 and 6 (0.829 to 1.000$)$ were more discriminant than ISSR3(0.458).

Comparison of the similarity values obtained with the five DNA fingerprinting methods that we used gave high and significant correlations between RAPD and BOX, RAPD and ERIC, and BOX and ERIC (Table 3). REP similarity values correlated with those obtained using BOX, RAPD, and ERIC; but these correlations should be interpreted carefully due to the low number of amplification products obtained with REP. No correlation or low correlations were observed between ISSR similarity values and those obtained with the other methods.

Most clusters found in the dendrograms obtained by BOX, ERIC, and RAPD fingerprinting techniques were similar (Figure 3). Specifically, bacterial isolates classified as E. coli, $H$. alvei and M. morganii formed individual clusters with more than $75 \%$ confidence, well separated from $P$. mirabilis isolates. Moreover, $P$. mirabilis isolates obtained from the same patient (patients 9, 10 and 18) from different data and/or sample sources and exhibiting the same antibiotic resistance and Dienes behavior, were genetically identical or very similar.

\section{Discussion}

Studies on the molecular epidemiology of infection due to Proteus species have employed a variety of methods, including ribotyping, PFGE, RAPD, and tandem-repeat microsatellite fingerprinting [14-19]. We showed that RAPD markers vary in their discriminatory ability. Some primers (OPZ20, OPX13, OPA11, OPZ08 and OPA19) showed high discrimination indices. The use of three primers (OPA11, OPX13 and OPZ8) allowed the characterization of all of the $P$. mirabilis isolates. The efficiency of RAPD markers for Proteus fingerprinting was previously reported by Binden et al. [17], in an epidemiological investigation of $P$. mirabilis from pregnant women and their neonates, and by Hoffman et al. [18] in a study of clinical isolates of $P$. penneri. In general, the relatively low reproducibility of RAPD typing limits its application to large-scale inter-laboratory studies. However, in our study RAPD showed high reproducibility between replications (within and between gels), which, associated with its high discrimination ability, makes this one of the most suitable methods for local Proteus epidemiological studies.

Among the primers selected for ISSR analysis, three primers showed high discriminatory power and allowed discrimination of all the isolates. Our data corroborate the conclusions reported by Cieslikowski et al. [19], who showed (GACA) and (CAAT) $)_{4}$ to be informative primers, and indicates that other primers, such as (AC) $)_{8} \mathrm{~T}$ and (AG) $)_{8} \mathrm{~A}$, could be useful in $P$. mirabilis studies. However, despite the large size of the primers, ISSR markers applied to $P$. mirabilis gave low reproducibility, and were not suitable for identification to the genus level.

The repetitive-DNA markers ERIC-PCR, and particularly BOX-PCR, were more informative than rep-PCR, which amplified only four bands in P. mirabilis. ERIC and BOX-PCR amplified 22 bands in Proteus, of which 19 were polymorphic. Repetitive-DNA markers have been used with success in the identification of a large number of Gram-negative bacteria, including Escherichia coli [12], Salmonella [10], Aeromonas [13], Burkholderia [11], Vibrio [24], among others.

Proteus mirabilis isolates obtained from the same patient (patients 9, 10 and 18) using different data and/or sample sources and exhibiting the same antibiotic resistance and Dienes behavior, exhibited identical or very similar RAPD, ERIC-PCR and BOX-PCR patterns, indicating that these molecular markers can be used to check for self contamination or strain persistence in a given patient.

In summary, we found that RAPD, ERIC-PCR and BOXPCR markers have a high discriminatory ability, allowing the genetic typing of clinical $P$. mirabilis isolates, which should prove useful for epidemiological studies of this bacterium.

\section{Acknowledgements}

The authors thank the Foundation of the University of Caxias do Sul for financial support, and CNPq for student fellowships.

\section{References}

1. Mobley H.L.T., Belas R. Swarming and pathogenicity of Proteus mirabilis in urinary tract. Trends Microbiol 1995;3:280-4.

2. Chow A.W., Taylor R.R., Yoshikawa T.T., Guze, L.B. A nosocomial outbreak of bacteria on struvite crystal habit and its importance in urinary stone formation. J Crystal Growth 1979;104:475-84.

3. O’Hara C.M., Brenner F.W., Miller J.M. Classification, identification, and clinical significance of Proteus, Providencia, and Morganella. Clin Microbiol Rev 2000;13:534-46.

4. Wassif C., Cheek D., Belas, R. Molecular analysis of metalloproteases from Proteus mirabilis. J Bacteriol 1995; $177: 5790-8$.

5. Rozalski A., Sidorczyk Z., Kotelko K. Potential virulence factors of Proteus bacilli. Microbiol Mol Biol Rev 1997;61:65-89.

6. Fraser G.M., Claret L., Furness R., Gupta S., Hugues, C. Swarmingcouples expression of the Proteus mirabilis hpmBA haemolysin operon. Microbiol 2002;148:2191-201.

7. Mobley H.L.T., Island D., Hausinger R.P. Molecular biology of microbial ureases. Microbiol Rev 1995;59:451-80.

8. Walker K.E., Moghaddame-Jafari S., Lockatell C.V., et al. ZapA, the IgA-degrading metalloprotease of Proteus mirabilis, is a virulence factor expressed specifically in swarmer cells. Molec Microbiol 1999;32:825-36.

9. Olive D.M., Bean P. Principles and applications of methods for DNA-based typing of microbial organisms. J Clin Microbiol 1999;37:1661-9.

10. Tikoo A., Tripathi A.K., Verma S.C., et al. Application of PCR fingerprinting techniques for identification and discrimination of Salmonella isolates. Curr Scie 2001;80:1049-52. 
11. Coenye T., Spilker T., Martin A., LiPuma J.J. Comparative assessment of genotyping methods for epidemiologic study of Burkholderia cepacia Genomovar III. J Clin Microbiol 2002;40:3300-7.

12. Seurinck S., Verstraete W., Siciliano S.D. Use of 16S-23S rRNA intergenic spacer region PCR and repetitive extragenic palindromic PCR analyses of Escherichia coli isolates to identify nonpoint fecal sources. Appl Environ Microbiol 2003;69:4942-50.

13. Szczuka E., Kaznowski A. Typing of clinical and environmental Aeromonas sp. strains by random amplified polymorphic DNA PCR, repetitive extragenic palindromic PCR, and enterobacterial repetitive intergenic consensus sequence PCR. J Clin Microbiol 2004;42:220-8.

14. Pignato S., Giammanco G.M., Grimont F., et al. Molecular characterization of the genera Proteus, Morganella, and Providencia by ribotyping. J Clin Microbiol 1999;37:2840-7.

15. Pfaller M.A., Mujeeb I., Hollis R.J., et al. Evaluation of the discriminatory powers of the Dienes test and ribotyping as typing methods for Proteus mirabilis. J Clin Microbiol 2000;38:1077-80.

16. Sabbuba N.A., Mahenthiralingam E., Stickler D.J. Molecular epidemiology of Proteus mirabilis infections of the catheterized urinary tract. J Clin Microbiol 2003;41:4961-5.

17. Bingen E., Boissinot C., Desjardins P., et al. Arbitray primed polymerase chain reaction provides rapid differentiation of Proteus mirabilis isolates from pediatric hospital. J Clin Microbiol 1993;31:1055-9.
18. Hoffmann G., Gajdos G., Czako M., et al. Diversity among clinical isolates of Proteus penneri detected by random amplified polymorphic DNA analysis. Zentbl Bakteriol 1998;288:351-60.

19. Cieslikowski T., Gradecka D., Mielczarek M., Kaca, W. Tandem tetramer-based microsatellite fingerprinting for typing of Proteus mirabilis strains. J Clin Microbiol 2003;41:1673-80.

20. CLSI. Performance standards for antimicrobial susceptibility testing, $17^{\text {th }}$ informational supplement. CLSI/NCCLS document M100-S17. Wayne, PA: National Committee for Clinical Laboratory Standards, 2007.

21. Versalovic J., Koeuth T., Lupski R.J. Distribution of repetitive DNA sequences in eubacteria and application to fingerprinting of bacterial genomes. Nucleic Acids Res 1991;9:6823-31.

22. Versalovic J., Schneider M., de Brujin F.J., Lupskin, J.R. Genomic fingerprinting of bacteria using repetitive sequence-based polymerase chain reaction. Methods Mol Cell Biol 1994; $5: 25-40$.

23. Hunter P.R., Gaston M.A. Numerical index of the discriminatory ability of typing systems: an application of Simpson's index of diversity. J Clin Microbiol 1988; 26: 2465-2466.

24. Wong H.C., Lin C.H. Evaluation of typing of vibrioparahaemolyticus by three PCR methods using specific primers. J Clin Microbiol 2001;39:4233-40. 